conversation and behaviour were quite natural, and none of those about me noticed anything wrong even when $I$ ex. plained what my symptoms were. At one time I tried lying down quietly, but I gave it up, as I found that thought succeeded thought only to be immediately blotted out, producing a most unpleasant effect and no inclination for sleep. Walking about the streets and among the people on the seashore was the pleasantest way of getting through the symptums. I tried no remedy, as when the symptoms were established I knew that the drug had been absorbed, and that in small quantity.

I am, Sirs, yours faithfully,

July 12 th, 1991

\section{RECOVERY FROM APPARENT DEATH FROM CHLOROFORM.}

To the Editors of THE LANCET.

SIRs, - At a time when there have been so many deaths from anæsthetics, it may be worth while to record the particulars of a recovery from what appeared to be death from chloroform. On the 2lst inst. my colleague, Mr. Algernon Moir, proceeded to chloroform a little girl five years old. On three previous occasions (twice by him and once by myself) she had been similarly anæsthetised without any thing unusual occurring. This time she had heen carefully prepared by abstinence from fooc as far as we knew, and the clothes were perfectly loose and everything in order. She took the drug in the usual fashion and went off quietly and quickly, and as soon as she appeared to be under its influence Mr. Moir sent me word that she was ready. In a few seconds, probably about thirty after he sent the message $I$ was in the room, and found Mr. Moir performing artificial respiration with one hand whilst he drew out the tongue with the other. The child appeared to me to be quite dead. I relieved him at once of the artiticial respiration and compressed the ribs from side to side myself, the air passing in and out freely. As the natural colour continued to leave the face and to be replaced by a livid pallor, I signed to him to use the amyl nitrite, which, according to our invariable custom, was close at hand. He at once held the open bottle to her mouth, through which the air was going freely, as he continued to draw out the tongue. My arms were beginning to give out, and my head to be affected with the amyl, when there was a sound as of the vocal cords moving, but I kept on until forced to rest for a moment, when I found that the breathing went on of itself, and that the child was alive. How long all this took I cannot tell. At such supreme moments time can only be measured by fatigue The matron and nurses who were present assure me that it was more than five minutes before signs of life appeared. I have had several cases of resuscitation since a similar recovery from death of a dog, an account of which you were good enough to publish on March 7 th, 1885, but none of such gravity as this. I firmly believe that without the amyl the child's life would not have been saved, and as I do not remember that it was tried in any of the cases of death which I have read lately I send this account in the hope that it may be used in cases like the above, and used promptly-of course, with the aid of artificial respiration. Mr. Moir is quite clear as to the mode of the very near approach to death in this instance. He says that pulse and respiration ceased at the same moment. The cause was not far to seek. Although the nurse had been most careful to keep her from eating anything, the child had managed to devour an apple, of which, on becoming conscious, she vomited the core, the stalk, and part of the skin. It appears, therefore, that this indigestible matter had caused reflex paraly sis of the cardiac and pulmonary centres, as at no time was there any obstruction to the passage of air.

I am, Sirs, your obedient servant,

Liverpool, July 29th, 1891 GEO. G. WALKER, F.R.C.S.

\section{EASY METHOD OF ENUCLEATING A RUPTURED EYEBALL. \\ To the Editors of THE LANCET.}

SIRs,--It has twice lately fallen to my lot to have to enucleate eyeballs that have been badly ruptured-one by the horn of a bullock, the other by an oyster.shell. The operation of enucleation is described as being more difficult when the eyeball is ruptured than when it is not ruptured-e.g, Nettleship on "Diseases of the Eye," p. 324, second edition; also Brudenell Carter on "Diseases of the Eye," p. 483, first edition. I have, however, not read or heard of a simple device which renders the operation as perfectly easy as when the globe is intact. The procedure is as follows. First stuff the globe with wool through the laceration in its coats. Secondly (and this must not be neglected or the wool will slip ont), unite the edges of the gap with a suture, leaving the ends long enough for any necessary traction. I can scarcely imagine this proceeding to be orjginal ; but its utility, and my ignorance of its having been previously practised, niust be my apology for trespassing on your valuable space.

I am, Sirs, yours faithfully,

James Ryley, M.D. Lond., M.R.C.S. Eng.

King-street, Great Yarmouth, Aug. 17th, 1891.

\section{THE CURE OF CONSUMPTION.}

\section{To the Editors of THE LANCET.}

SIRS,-I was much surprised to find THE LANCET noting with approval the letter of "Army Medical Reserve," in which he implies that I have been guilty of a grave breach of the unwritten laws of the profession in not bringing my investigations on this subject before the profession, and 1 feel sure that as an act of simple justice you will at once enable me to state that I am not responsible for its nonappearance in your columns. To me it has been and is a source of great regret and much disappointment that the arguments and practical evidence that show that consumption can be with certainty prevented and cured have not been prominently brougho before the profession. I am satisfied that if that course were adopted it would lead to a thorough practical investigation and the universal acceptance of the principles for which $\mathrm{I}$ have been so long contending. Will THE LANCET afford me that opportunity : It is evident that physical development, as I use the term, and the system that certainly has and is curing consump. tion, are totally misunderstood by the writer of the comments above referred to.

I am, Sirs, yours faithfully,

Bentinck-street, W., Ang. 11th, 1891.

GoDFREY W. HambletoN.

* * We have certainly afforded Mr. Hambleton an oppor. tunity for expressing his views (vide THE LANCET, 1887-8); but what is really required is an impartial investigation of them by a committee of medical experts, and he should endeavour to gain the coöperation of one of our medical societies to this end. He might surely have taken advantage of last wcek's Congress to ventilate his subject.-ED. L.

\section{THE TUBERCULOSIS CONGRESS}

\section{(From our Paris Correspondent.)}

This biennial Congress, inaugurated by Professor Verneuil and Dr. L. H. Petit, one of the librarians of the Paris Faculty, has just brought its second session to a close, and English members of our profession will be glad to be made acquainted with the results of its deliberations on the allabsorbing subject of the disease science is making such strenuous efforts to master. It may at once be said that no startling novelty in the shape of remedial measures dates its birth from this rénion, the most fruitful points of discussion having had reference to the relations existing between tubercle bacilli as met with in different animals. It is manifestly of the most vital importance to arrive at some decision as to the identity or non-identity of the micro organisms determining the evolution of the tuberculous process in man, cows, birds, and rodents. With regard to avian tuberculosis, M. Vignal comes to the conclusion that the bacillus characterising it differs in toto from the human bacillus. M. Vignal, in effect, inoculated with the sputa of tuberculous patients a series of guiuea-pigs, which all died whereas a pheasant, which had undergone successive and simultaneous inoculations, survived. MM. Strauss and 